\title{
Resistance of concrete and expanded clay concrete under periodic external influences
}

\author{
Valery Vyrovoy, Oksana Korobko*, Vladimir Sukhanov, and Yuri Zakorchemny \\ Odessa State Academy Civil Engineering and Architecture, Didrihsona st. 4, 65029 Odessa, Ukraine
}

\begin{abstract}
The purpose of the work is to increase resistance of concrete in conditions of multiple freezing-thawing and wetting-drying cycles. An important property of concrete is its ability to adapt to the periodical effect of external factors by self-organization of the structure. It assumes the presence at the material of active elements capable of changing their parameters adequately to impacts. Such elements include cracks and inner surfaces of partition as integral elements of the structure of any material. Sets of active elements can be to obtained by directing the structural organization of concrete. The operating factor of structure formation can be a change in the ratio of adhesion and cohesive bonding forces at the surface of partition between the matrix material and the fillers. Concrete the structure of which was initiated by selective adhesion of a matrix to the surface of fillers differed in the raised values of properties. Structural potential has determined resistance of concrete at freezing-thawing and wetting-drying. Sets of active elements of concrete structure are the factors of safe functioning of building constructions in conditions of influence of the operating environment.
\end{abstract}

\section{Introduction}

At operation concrete as a material of building constructions undergoes influence of periodic changes of temperature and humidity of the environmental and reacts to them by spontaneous reorganization of the structure. Structural adaptation of the material provides stability of initial level of properties of concrete under the influence of changing stress. This is, to a large extent, determined by changes the parameters of technological cracks and inner surfaces of partition as active elements of the structure, capable in a timely manner of responding to external influences [1]. Poly-structure of concretes implies mutual influence and interaction of the structural levels at all periods of their life cycle. Therefore, parameters of level of interaction of a matrix material with fillers can be used as the factor of regulation of processes of microstructure formation and conditions of initiation and development of cracks which arise in technological period of production of a construction.

Change of a ratio of adhesive and cohesive bonding forces at the surface of partition between the matrix and the surface of fillers influences technological damage of concrete as the total quantity of cracks and inner surfaces of partition in material volume. Technological cracks pass into rank operational cracks under the first influence of the external environment. Sets of technological cracks determine dynamics of change of damage of concretes in period their functioning as realization of adaptation effects. Material 
properties remain at the predetermined level as result of structure self-organization. On the basis of the above, the purpose of the study is to increase the resistance of concrete under freezing-thawing and wetting-drying at the expense of the directed organization their structure by changing the ratio of adhesive and cohesive bonding forces at the surface of partition between the matrix material and the fillers.

\section{Analysis of recent research}

In structural materials science the structural approach, which is based on the determining role of the structure in ensuring the properties of construction as system of a certain type, is becoming increasingly important $[1,2,3,4,5]$. This is consistent with the poly-structural approach to building composites, which takes into account the interdependence of different scale structural levels [6]. There are new possibilities for the directed organization of the structure of concrete as a complex dynamic open system by changing the initial conditions for the structure formation of individual subsystems - the levels of structural heterogeneities $[7,8,9,10]$. It is shown in the works $[1,9]$ that cracks and inner surfaces of partition as integral elements of the structure determine structural changes in the periods of production and operation of materials. Adaptation of composites as open systems to external influences mainly depends on their damage by technological and operational cracks and inner surfaces of partition [11]. This does not exclude the certain effect of conservative and meta-stable structural elements (relict zone cement particles, pores, capillaries and other) on the behavior of materials $[12,13,14]$. The sets of cracks and inner surfaces of partition can be received at different structural levels given their characteristic elements. The change of conditions of the interaction of the matrix component with fillers allows providing damage of concrete under which the effects of adaptation favorable for resistance of a material will occur. This, in turn, will contribute to the safety of the functioning of constructions under the influence of temperature and humidity of the environment.

\section{Object and methods of the research}

In order to achieve the objective of the research, the following tasks were set: - to analyze the dynamics of changes of damage as a structure characteristic at low-cycle fatigue of the concrete; - to determine the coefficients of resistance of concrete and expanded clay concrete in conditions of repeated external exposures.

The object of researches is the structure of concrete as open self-organizing system.

Researches were carried out on samples-cubes with the size of $100 \times 100 \times 100 \mathrm{~mm}$, made of concrete and expanded clay concrete.

The surface of the grain part of granite rubble and expanded clay gravel was processed by hydrophobic agent. It has provided various ratios of adhesive and cohesive bonding forces at the surface of partition between the cement matrix and the surface of fillers: $R_{A}>R_{C} ; R_{A}<R_{K} ; R_{A}=R_{C}\left(R_{A}\right.$ is the adhesion value of the matrix to the surface of the fillers; $R_{C}$ is the cohesive strength of the matrix material.

Controlled properties of concrete: technological and operational damage $\left(K_{d}\right)$, average density $\left(\rho_{\omega}, \mathrm{kg} / \mathrm{m}^{3}\right)$, the volume of open capillary pores $\left(P_{o}, \%\right)$, water absorption $(W, \%)$, modulus of elasticity $\left(E, \mathrm{mPa} \cdot 10^{-3}\right)$, strength $\left(f_{\text {ck.cube }}, \mathrm{mPa}\right)$, weight $(\mathrm{m}, \mathrm{gr})$, resistance $\left(K_{\text {res }}\right)$ of concrete and expanded clay concrete under periodic freezing-thawing and wettingdrying.

Concrete damage was determined using the coefficient of damage [11] as the ratio:

- $K_{d}=\Sigma L / S, \mathrm{~cm} / \mathrm{cm}^{2}, \Sigma L_{i}, \mathrm{~cm}$, is the total length of crack and inner surfaces of partition boundaries on the sample surface; $S, \mathrm{~cm}^{2}$, is the fixed surface area of the sample; 
- $K_{d}=/ \sum L_{i} / L_{i}, \sum L_{i}, \mathrm{~cm}$, is the total length of crack and inner surfaces of partition boundaries on the sample surface (the actual crack); $L_{i}, \mathrm{~cm}$, is the geodesic line (the shortest distance between the exit points of the actual crack at end faces of the sample).

Measurements were made on 5 sides of each sample, except for the top, calculating $K_{d}$ as the arithmetic mean of the values obtained.

Coefficients of resistance of concrete and expanded clay concrete after 500 and 100 cycles of alternating freezing-thawing and wetting-drying were calculated on the basis of the obtained values of properties.

The coefficients of resistance of concrete were determined as: $K_{f}=Q^{\text {Ncycles }} / Q^{28}: Q^{\text {Ncycles }}$ the value of property of the samples after a certain quantity of exposure cycles; $Q^{28}$ - the value of property of the samples after 28 days of normal hardening.

\section{Results of the research}

In the case of a statistically arbitrary arrangement of grains in the volume of concrete, the groups of fillers form the ordered cells, restricting this or that part of the matrix material. Even with the same concrete mix, cells of different shapes and sizes coexist at the level of the macrostructure with different ratios of adhesion and cohesive bonding forces at the surfaces of partition between the matrix and the surface of the fillers. In each cell, the individual initial conditions for the structure formation of the cement matrix are provided [15]. This leads to different periods of formation of the structure and manifestation of the volume deformations of the matrix material and the properties of the cement stone in local volumes of concrete. Concretes of industrial mixes include sets of structural cells with multi-variant geometrical parameters at given conditions of interaction of the matrix with the surface of fillers. To increase the variety of cells can be by changing the ratio of the values of cohesion and adhesion on the surfaces of partition between the matrix and the fillers. Cells are relatively autonomous interconnected concrete parts, in which sets of different structural elements are provided. The interaction of these elements determines the structure potential and the level of properties of the entire material prior to operation.

The researches carried out on the models of structural cells showed that the values of the damage of the cement stone in different cells varied up to 2,5 times, depending on the ratio $R_{A} / R_{C}$. The value of $K_{d}$ changed on $15-45 \%$ at variation of the form of cells, at variation of orientation of the fillers in the cells by $18-40 \%$. Distinction of the value of matrix damage was $22-34 \%$ at various ratios of $R_{A} / R_{C}$.

Difference of the structure of the cement matrix in individual concrete cells was confirmed by a wide range of quantitative values of the strength and speed of propagation of ultrasonic waves in local zones of concrete samples. At the wide variety of cells of the cells, the greatest range of the mechanical and acoustic characteristics in the sample material is ensured. It testifies to coexistence in the concrete of various density sections of the matrix material. The values of strength of a cement stone in various cells of the same sample differed by $13-33 \%$. At the wide variety $R_{A} / R_{C}$ ratios, the range of the values of the properties was in 2 times more, than in samples with complete or imperfect adhesion of the matrix to the surface of the fillers. The range of cement matrix properties in the local volumes of concrete samples at $R_{A}>R_{C}$ and $R_{A}<R_{C}$ can be explained by the influence of the geometrical parameters of the cells on the structure formation of the matrix material and the properties of concrete. A more varied set of cells in concretes is formed by selective adhesion of the cement matrix to the surface of fillers $\left(R_{A}=R_{C}\right)$.

Depending on the conditions of interaction of the matrix material with the surface of the fillers, the concrete mixes were corrected for the $\mathrm{W} / \mathrm{C}$ values. 
Concrete grade $\mathrm{C} 25 / 30$ at $\mathrm{R}_{\mathrm{A}}<\mathrm{R}_{\mathrm{C}}$ (mix I); $\mathrm{C} 30 / 35$ at $R_{A}>R_{C}$ (mix II); $\mathrm{C} 32 / 40$ at $R_{A}=R_{C}$ (mix $I I I)$ were obtained in conditions of constant mobility of concrete mixture.

Expanded clay concrete grade $\mathrm{LC} 12 / 13$ at $\mathrm{R}_{\mathrm{A}}>\mathrm{R}_{\mathrm{C}}(\operatorname{mix} I)$ and grade $\mathrm{LC} 16 / 18$ at $\mathrm{R}_{\mathrm{A}}<\mathrm{R}_{\mathrm{C}}$ (mix $I I$ ) and $R_{A}=R_{C}$ (mix $\left.I I I\right)$ was obtained at the various ratios $R_{A} / R_{C}$ with corresponding values of properties.

The formation of structural blocks at all levels of heterogeneity is an equifinal result of diverse processes and phenomena of concrete structure organization $[16,17,18,19,20]$. It initiates the spontaneous generation and self-development of the surfaces of partition between the individual blocks. These elements can be transformed into cracks and inner surfaces of partition under the influence of own deformations of the material. In turn, cracks and inner surfaces of partition are integral elements of the structure that determine the heterogeneity of concrete before the beginning of functioning of the construction. Cracks and inner surfaces of partition provide the possibility of manifesting various mechanisms of structure adaptation to the negative influences of the external environment. A feature of these elements is the ability to react instantly to virtually any external influences, timely changing own parameters and initiate action of structural elements with slow responses to the rapidly changing operating conditions of material. The coexistence of cracks and inner surfaces of partition causes the possibility of self-organization of the material that prevents the destruction of the construction [21, 22]. The manifestation of adaptation effects connected with self-development of cracks can be realized as the transformation of cracks into inner surfaces of partition. It stops the growth of cracks, increases the discreteness of composites and creates preconditions for the localization of deformations and stresses in individual blocks of material. It contributes to the dissipation of excess energy on the banks of various cracks and inner surfaces of partition. The ability of cracks to redistribute deformations between blocks prevents their local accumulation that reduces the general stress-strain state of the material. In the local volumes of macrostructure of concrete, a variety of sets of active elements are formed, which at the level of the material structure integrative determine its functional potential and the conditions of interaction with the environment.

In the conditions of the experiment, the best properties were of concretes, the structure of which was initiated by the selective adhesion of the matrix to the surface of the fillers.

At $R_{A}=R_{C}$, the structure is formed, which leads to a decrease values of water absorption and porosity of concrete and expanded clay concrete at increasing values of their average density, technological damage, strength and modulus of elasticity. The change in the ratio of adhesive and cohesive bonding forces at the surface of partition between the matrix material and fillers makes it possible to increase the concrete strength up to $26 \%$ and expanded clay concrete strength up to $10 \%$ after 28 days of normal hardening, at the age of 720 days - up to $24 \%$ and $12 \%$, respectively. The modulus of elasticity increased by $12-$ $21 \%$, the decrease values of water absorption was $8-14 \%$. The volume of the open capillary pores decreased to $18 \%$ at the organization of structure of concrete in conditions of selective adhesion of the matrix to the fillers. The speed of passage of ultrasonic waves through concrete has decreased from $U=3400 \mathrm{~m} / \mathrm{s}$ to $U=3200 \mathrm{~m} / \mathrm{s}$, through expanded clay concrete - from $U=3200 \mathrm{~m} / \mathrm{s}$ to $U=2900 \mathrm{~m} / \mathrm{s}$. Increasing the density of materials should lead to increase of their resistance under action of external factors.

Analysis of the results showed that the change of ratio of $R_{A}$ and $R_{C}$ values determines the technological (initial) damage of concrete, the values of $K_{d}$ of which, under the experimental conditions, differ by $11-15 \%$. It, in turn, predetermined the dynamics of changes of material operational damage under repeated external exposures, fig. 1 . 


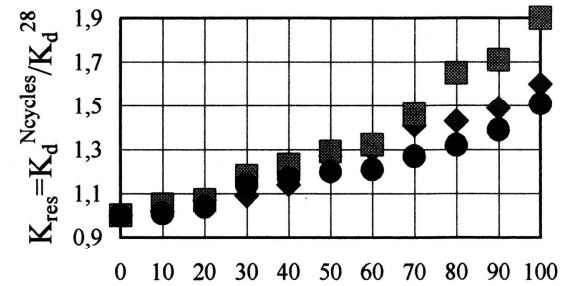

Cycles of freezing-thawing

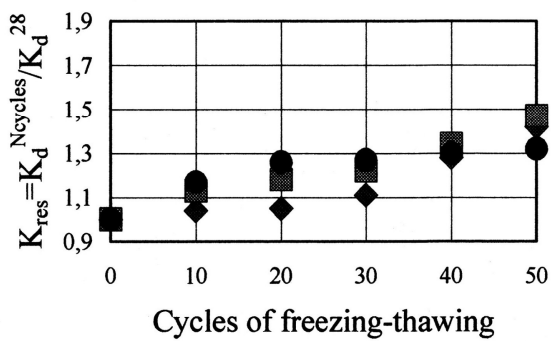

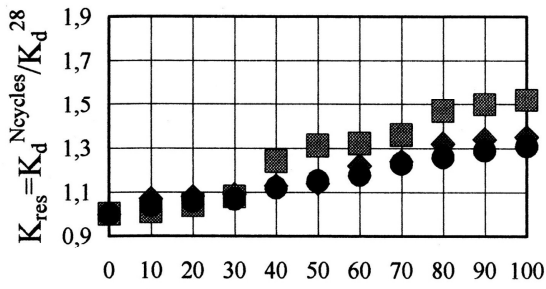

Cycles of freezing-thawing

a)

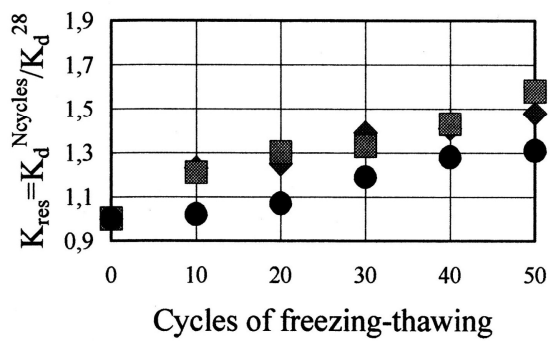

b)

Fig. 1. Coefficients of resistance, $K_{d}$, of concrete (a) and expanded clay concrete (b) at low-cycle fatigue. $K_{d}=K_{d}^{\text {Ncycles }} / K_{d}^{28}: K_{d}^{\text {Ncycles }}$ - the value of damage of the samples after a certain quantity of exposure cycles; $K_{d}^{28}$ - the value of damage of the samples after 28 days of normal hardening. $\bullet-R_{A}<R_{C} ;--R_{A}>R_{C} ; \bullet-R_{A}=R_{C}$.

As a result of periodic external exposures, damage of concrete increased by $26-48 \%$, expanded clay concrete to $24-37 \%$. Values $K d$ of concretes with the structure formed under the influence of selective adhesion of the matrix to the surface of fillers were $20-25 \%$ less than the values of concrete damage at other $R_{A} / R_{C}$ ratios. It can be explained by the fact that the cracks were closed in the structural blocks of the cement matrix, which did not allow them to grow to the dimensions dangerous for this level.

The development of cracks in materials with block structure is a discrete-continuous process of incremental growth of cracks after each cycle of repeated influences. The following structural transformations depend on the previous changes of the parameters of cracks and inner surfaces of partition due to the fact that new conditions are constantly created for the redistribution of deformations and stresses on the boundaries of cracks.

The change of the parameters of cracks and inner surfaces of partition is reflected on the values of the coefficient of concrete resistance and expanded clay concrete in case of low cycle fatigue caused by cycles of periodic changes of temperature $(T)$ and humidity $(W)$ of the environment (Table 1). Increased values of the properties provided by the structure of concrete under the experimental conditions are highlighted in the color.

The analysis of the coefficients of resistance of concrete and expanded clay concrete showed that the concretes, whose structure was organized at the initial condition $R_{A}=R_{C}$, were more adapted to the influence of alternating external factors.

After 100 cycles of periodic exposures, the strength of concrete of mix III practically did not change, the modulus of elasticity of concrete increased by $11 \%$, the modulus of elasticity of expanded clay concrete has decreased by $10 \%$. The volume of open capillary pores has decreased by $7-10 \%$, water absorption by $0-5 \%$ (concrete) and $14-16 \%$ (expanded clay concrete), the mass loss was not more than $2 \%$. 
Table 1. Resistance of concrete and expanded clay concrete at low cycle fatigue.

\begin{tabular}{|c|c|c|c|c|c|c|c|c|c|c|c|c|c|c|c|}
\hline \multirow{3}{*}{$\mathrm{N}^{\text {cycle }}$} & \multirow{2}{*}{\multicolumn{3}{|c|}{$\begin{array}{c}K_{\text {res }}=f_{c k}^{N_{c k}}{ }^{\text {Ncle }} / f_{c k}^{28} \\
\text { Mixes }\end{array}$}} & \multicolumn{3}{|c|}{$K_{\text {res }}=E^{\text {Ncycle }} / E^{28}$} & \multicolumn{3}{|c|}{$K_{\text {res }}=W^{\text {Ncycle }} / W^{28}$} & \multicolumn{3}{|c|}{$K_{\text {res }}=\Pi_{o}^{\text {Ncycle }} / \Pi_{o}^{28}$} & \multicolumn{3}{|c|}{$K_{\text {res }}=m^{\text {Ncycle }} / m^{28}$} \\
\hline & & & & \multicolumn{3}{|c|}{ Mixes } & \multicolumn{3}{|c|}{ Mixes } & \multicolumn{3}{|c|}{ Mixes } & \multicolumn{3}{|c|}{ Mixes } \\
\hline & I & II & III & I & II & III & I & II & III & I & II & III & $\mathrm{I}$ & II & III \\
\hline \multicolumn{16}{|c|}{ Concrete } \\
\hline$T=0$ & 1 & 1 & 1 & 1 & 1 & 1 & 1 & 1 & 1 & 1 & 1 & 1 & 1 & 1 & 1 \\
\hline$T=50$ & 0.97 & 0.98 & 0.99 & 1.04 & 0.96 & 1.24 & 0.85 & 0.93 & 0.76 & 0.84 & 0.90 & 0.77 & 0.99 & 0.98 & 0.99 \\
\hline$T=100$ & 0.96 & 0.96 & 0.98 & 1.02 & 0.94 & 1.12 & 0.97 & 0.99 & 0.95 & 0.92 & 0.94 & 0.93 & 0.95 & 0.95 & 0.97 \\
\hline $\mathrm{W}=0$ & 1 & 1 & 1 & 1 & 1 & 1 & 1 & 1 & 1 & 1 & 1 & 1 & 1 & 1 & 1 \\
\hline $\mathrm{W}=50$ & 1.02 & 1 & 1 & 1.28 & 1.11 & 1.32 & 0.90 & 0.97 & 0.88 & 0.88 & 0.93 & 0.88 & 0.98 & 0.98 & 0.99 \\
\hline $\mathrm{W}=100$ & 1 & 0.98 & 0.99 & 1.22 & 1.02 & 1.29 & 1.04 & 1.03 & 1.0 & 0.99 & 0.98 & 1.0 & 0.95 & 0.95 & 0.98 \\
\hline \multicolumn{16}{|c|}{ Expanded clay concrete } \\
\hline $\mathrm{T}=0$ & 1 & 1 & 1 & 1 & 1 & 1 & 1 & 1 & 1 & 1 & 1 & 1 & 1 & 1 & 1 \\
\hline $\mathrm{T}=50$ & 0.97 & 0.98 & 1 & 0.86 & 0.95 & 0.93 & 0.78 & 0.82 & 0.73 & 0.76 & 0.81 & 0.71 & 0.98 & 0.98 & 1 \\
\hline $\mathrm{T}=100$ & 0.95 & 0.95 & 0.98 & 0.82 & 0.9 & 0.89 & 0.89 & 0.92 & 0.83 & 0.85 & 0.87 & 0.81 & 0.95 & 0.95 & 0.97 \\
\hline $\mathrm{W}=0$ & 1 & 1 & 1 & 1 & 1 & 1 & 1 & 1 & 1 & 1 & 1 & 1 & 1 & 1 & 1 \\
\hline $\mathrm{W}=50$ & 1 & 1.01 & 1.03 & 1.11 & 1.17 & 1.03 & 0.92 & 1.01 & 0.96 & 0.91 & 0.96 & 0.98 & 0.99 & 0.97 & 0.99 \\
\hline $\mathrm{W}=100$ & \begin{tabular}{|l|}
0.97 \\
\end{tabular} & \begin{tabular}{|l|}
0.99 \\
\end{tabular} & 0.99 & 1.07 & 1.12 & 0.99 & 1.12 & 1.15 & 1.16 & 1.06 & 1.08 & 1.16 & 0.96 & 0.95 & 0.96 \\
\hline
\end{tabular}

For concretes of mixes $I$ and $I I$, the strength values decreased to $5 \%$ at change of the modulus of elastic modulus of up to $18 \%$, an increase in water absorption by $3-13 \%$ and the open porosity by $11-14 \%$, loss of weight reached $5 \%$.

Difference of initial conditions has provided structures which potential allows the use of building products on the basis of concrete and expanded clay concrete at periodic variations of humidity and temperature of the environment.

\section{Conclusions}

The carried out researches and the analysis of results allow concluding, that increase of resistance of concrete at alternating external influences is provided by the directed organization of their multilevel structures. The initial conditions for the formation of the structure can be determined by changing the ratio of adhesion-cohesive bonding forces at the surface of partition between the matrix material and the surface of the fillers. The reorganization of the concrete structure determines the resistance of concrete at low-cycle fatigue and the preservation of the product properties level. The dynamics of change of damage as a manifestation of the effects of adaptation of concrete during the operation of the product depends on the structural potential in the form of sets of technological cracks and inner surfaces of partition. Concretes with a structure formed by selective adhesion of the cement matrix to the fillers had the raised parameters of quality and were better adapted to low-cycle fatigue stress. The variety of the initial conditions of interfacial interactions has provided increase strength of concrete to $26 \%$ and strength of expanded clay lightweight concrete to $10 \%$, modulus of elasticity to $12-21 \%$ at reduction of total porosity by $18 \%$ and water absorptions by $8-14 \%$. Interference and interaction of the active elements of the structure is a factor of the safe functioning of building constructions.

\section{References}

1. V. Vyrovoy, V. Dorofeev, V. Sukhanov, Composite building materials and constructions. Structure, self-organization, properties (TES, Odessa, 2010)

2. V. Babkov, V. Mokhov, S. Kapitonov, P. Komokhov, Structure formation and destruction of cement concrete (Public administration of the press, Ufa, 2002) 
3. Yu. Bazhenov, A. Danilov, I. Garkina, etc., System approach to development and quality management of building materials (PALEOTYPE, Moscow, 2006)

4. L. Sheynich, E. Pushkareva, Processes of self-organization of the structure of building composites (Gamma Print, Kyiv, 2009)

5. F. Campbell, Structural Composite Materials (ASM International Press, Ohio, 2010)

6. V. Solomatov, The development of the polystructural theory of composite building materials, Proceedings of high schools. Construction and architectur, 8, 58-64 (1985)

7. V. Mogilevsky, Methodology of systems (Economics, Moscow, 1999)

8. Prangishvili, System approach and system-wide regularities (SINTEG, Moscow, 2000)

9. V. Vyrovoy, O. Korobko, V. Sukhanov, E. Rogniuk, collection of scientific works of OSACEA, 55, 57-63 (2014)

10. V. Vyrovoy, A. Gerega, V. Dorofeev, V. Sukhanov, J. Modern concrete. Prospects of development, 15-17 (2010)

11. V. Dorofeev, V. Vyrovoy, Technological damage of building materials and constructions (Gorod masterov, Odessa, 1998)

12. V. Chernyavsky, Adaptation of abiotic systems: concrete and reinforced concrete (DNYRT, Dnepropetrovsk, 2008)

13. J. Stark, V. Bernd, Durability of Concrete (Oranta, Kiev, 2004)

14. Durability of Concrete and Cement Composites by C.L. Page, M.M. Page (CRC Press, 2007).

15. V. Vyrovoy, O. Korobko, V. Panasyuk, J. Tech. of conc., 5-6, 16-18 (2016)

16. L. Shpinova, V. Chikh, M. Sanitsky, etc, Physico-chemical basis for the formation of the structure of cement stone (Vishcha school, Lviv, 1981)

17. Pascenco, E. Myasnikov, V. Vimen, Cement Theory (Budivelnik, Kiev, 1991)

18. J. Stark, B. Wicht, Cement and lime (Oranta Kiev, 2008)

19. Y. Ballim, P. Graham, Cem Concr Compos., 26 (5), 417-426 (2004)

20. P. Metha, P. Monteiro, Concrete: Microstructure, Properties and Materials (McGrawHill, New York, 2006.

21. O. Korobko, V. Sukhanov, V. Vyrovoy, V. Tofanilo, Collection of scientific works of KSABU, 3 (29), 114-121 (2014)

22. V. Shevchenko, Yu. Antonyuk, Collection of scientific works of conf. "Structure formation, strength and destruction of composite building materials and constructions", 149-152 (2018) 